\title{
POST-PRINT
}

Submitted, accepted and published in

Microporous and Mesoporous Materials 179, 69-77 (2013); DOI:

10.1016/j.micromeso.2013.05.012

\section{Tailored synthesis of organized mesoporous aluminas prepared by non-ionic surfactant templating using a Box-Wilson CCF design}

\author{
S. de Llobet ${ }^{\mathrm{a}}$, H. Purón ${ }^{\mathrm{b}}$, J.L. Pinilla ${ }^{\mathrm{b}, 1}$, R. Moliner ${ }^{\mathrm{a}}$, M. Millán ${ }^{\mathrm{b}, *}$, I. Suelves $^{\mathrm{a}}$, \\ ${ }^{a}$ Instituto de Carboquímica. CSIC. Miguel Luesma 4, Zaragoza 50018, Spain \\ ${ }^{b}$ Department of Chemical Engineering, Imperial College London, London SW7 2AZ, \\ $U K$
}

\begin{abstract}
Organized mesoporous aluminas (OMA) are materials that present interesting properties as catalytic supports in reactions in which bulky molecules are involved. In this work, a number of OMA were prepared using a non-ionic structure directing agent (a tri-block co-polymer). The study of the quantitative influence of some OMA synthesis conditions (water aluminium ratio $\left(\mathrm{H}_{2} \mathrm{O}: \mathrm{Al}\right)$, ageing temperature $\left(\mathrm{T}_{\mathrm{ag}}\right)$, and calcination heating rate $\left(\mathrm{r}_{\mathrm{cal}}\right)$ ) on the resulting OMA textural properties (specific surface area $\left(\mathrm{S}_{\mathrm{BET}}\right)$, pore volume $\left(\mathrm{V}_{\mathrm{p}}\right)$ and average pore diameter (APD)) was carried out using a Box-Wilson Central Composite Design Face Centred (CCF, $\alpha: \pm 1)$. The models obtained provided a satisfactory adjustment of the experimental data. $\mathrm{H}_{2} \mathrm{O}: \mathrm{Al}$ was found to be the most

\footnotetext{
${ }^{1}$ Present address: Instituto de Carboquímica. CSIC. Miguel Luesma 4, 50018 Zaragoza (Spain) * Corresponding authors:

(I.S.) Tel. +34976733977; Fax: +34 976733318; e-mail address: isuelves@icb.csic.es

(M.M.) Tel. +44(0)2075941633; Fax: +44(0)2075945638; e-mail address: marcos.millan@imperial.ac.uk
} 
influencing model term. The influence of $T_{a g}$ and $r_{c a l}$ interactions on $S_{B E T}$ and $V_{p}$ was found to be significant. Representative OMA with well differentiated pore size distributions were characterized by $\mathrm{N}_{2}$ adsorption, XRD and TEM.

Keywords: Organized mesoporous alumina, non ionic surfactants, experiment design 


\section{Introduction}

Organized mesoporous aluminas (OMA) have recently attracted the attention of the scientific community due to their interesting textural properties, such as large surface areas, tuned pore size diameter and various surface properties which may vary depending on their specific synthesis procedure [1]. These characteristics make these materials promising candidates as support in catalytic processes in which large molecules are involved, such as hydrotreating of heavy oil fractions. Available mesoporosity in catalysts used in these processes is of paramount importance in order to facilitate the diffusion of reactants and products by avoiding steric hindrance as well as to reduce catalyst deactivation by coke [2]. Mesoporous materials favour the access of asphaltenes from heavy oils into the catalytic structure, promoting hydrodeasphalting (HDA) and hydrodemetalisation (HDM) reactions[3].

The methods developed to synthesise OMA are based on the use of various structuredirecting agents, which can be classified into cationic, anionic or neutral, as reviewed in $[1,4]$. The first report on the method of neutral or non ionic surfactant, published by Bagshaw et al. [5, 6], was based in the hydrolysis of an alkoxide (tri-secbutoxyaluminium) employing structure director agents poly(ethylene oxide) (PEO) based diblock (Tergitol, Igepal, Triton) or triblock co-polymers (Pluronic 64L). The non ionic templating procedure has successfully been applied for OMA synthesis using a number of different aluminium precursors, such as other alkoxides (sec butoxide) [6-8], nitrate [9], chloride [9-11] and $\mathrm{Al}_{13}$ Keggin oligocation [8, 9].

Several studies can be found in the literature addressing the effect of the preparation conditions on the textural parameters of the synthesised aluminas. Focusing on the non ionic templating method, alongside the structure directing agent and the aluminium 
source used, the synthesis process variables under study are commonly $\mathrm{H}_{2} \mathrm{O}: \mathrm{Al}$ ratio (also called hydrolysis ratio), ageing temperature and calcination temperature program (final calcination temperature and dwell time). The effect of $\mathrm{H}_{2} \mathrm{O}$ : $\mathrm{Al}$ ratio was shown to be determinant in the obtained average pore diameter (APD) [12]. High hydrolysis ratios led to an increase of the $\mathrm{H}_{2} \mathrm{O}$ :co-solvent ratio. As a consequence, the micelle radii augments [13] and thus, an increase in the pore size was observed [12]. However, no definitive trend could be inferred between the hydrolysis ratio and specific surface area $\left(\mathrm{S}_{\mathrm{BET}}\right)$ and pore volume $\left(\mathrm{V}_{\mathrm{p}}\right)$.

The study of the influence of the ageing temperature from 25 to $90{ }^{\circ} \mathrm{C}$ [7] revealed that $\mathrm{V}_{\mathrm{p}}$ decreased with increasing temperature, although it was not significantly correlated to the final $S_{\mathrm{BET}}$. Pores sizes were shifted to smaller diameters at higher temperatures. The same results were observed in [9] with an increase in ageing temperature from 45 to 90 ${ }^{\circ} \mathrm{C}$.

An increase in final calcination temperatures (from 500 to $800^{\circ} \mathrm{C}$ ) led to a decrease in $\mathrm{S}_{\mathrm{BET}}$ and no significant change in the APD or $\mathrm{V}_{\mathrm{p}}$ [7]. Other authors also showed a decrease in $\mathrm{S}_{\mathrm{BET}}$ when calcination temperature was increased [14, 15]. Calcination times of $2 \mathrm{~h}$ were needed to stabilise $\mathrm{S}_{\mathrm{BET}}$ [7]. In the same work, it was shown that prolonged calcination times at $650{ }^{\circ} \mathrm{C}$ (up to $32 \mathrm{~h}$ ) did not affect negatively the structural stability of the prepared mesoporous aluminas.

The study of the influence of the calcination heating rate has attracted considerably less attention, even though this treatment, aimed at surfactant removal, might have an enormous influence on the final textural properties, as pointed out in [1]. This was attributed to the fact that surfactant combustion is highly exothermic and might cause a collapse of the pore structure. Calcination heating rates lower than $5^{\circ} \mathrm{C} \cdot \mathrm{min}^{-1}$ are 
commonly used in the non ionic templating method [1], although to the best of our knowledge, the influence of the variation of heating rate in the textural properties of OMA prepared by the non ionic templating method has not been studied.

Despite the number of works found in literature, a systematic approach using statistical tools is highly recommended in order to elucidate the effect of the synthesis variables studied on the final properties of the aluminas and to determine the possible synergies between the studied variables. Recently, statistical tools have been used to address the influence of some synthesis variables on the textural properties of the OMA prepared using cationic structure directing agent [16]. Results showed that the main factor influencing the textural properties of the synthesised aluminas was $\mathrm{H}_{2} \mathrm{O}: \mathrm{Al}$ ratio.

In this work, the quantitative influence of some OMA synthesis conditions (water aluminium ratio $\left(\mathrm{H}_{2} \mathrm{O}: \mathrm{Al}\right)$, ageing temperature $\left(\mathrm{T}_{\mathrm{ag}}\right)$, and calcination heating rate $\left.\left(\mathrm{r}_{\mathrm{cal}}\right)\right)$ was studied by its effects on the textural properties ( $\mathrm{S}_{\mathrm{BET}}, \mathrm{V}_{\mathrm{p}}$ and APD) using a nonionic structure directing agent (a tri-block co-polymer). The manuscript is divided into two sections: in the first one, the influence of the different synthesis conditions on the textural properties is studied and correlated using statistical tools. An augmented model following a Box-Wilson Central Composite Design Face Centred (CCF, $\alpha: \pm 1)$ was implemented, providing a satisfactory adjustment of the experimental data obtained. Secondly, a thorough study about the textural and structural properties of some representative OMA synthesised is presented.

\section{Experimental}

\subsection{Materials and Synthesis of OMA}


Aluminum isopropanoxide, Pluronic F127 ((EO) $\left.)_{106}(\mathrm{PO})_{70}(\mathrm{EO})_{106}\right)$ and propanol were purchased from Sigma Aldrich. Absolute ethanol was purchased from VWR UK.

The synthesis of the different aluminas was adapted from a protocol for mesoporous alumina synthesis available in the literature [12]. For each sample of alumina, $50 \mathrm{~g}$ of aluminum isopropanoxide were dissolved in $100 \mathrm{~mL}$ of ethanol and $100 \mathrm{~mL}$ of propanol, while stirring the mixture at $50{ }^{\circ} \mathrm{C}$. When it was homogeneous, $34.7 \mathrm{~g}$ of nonionic surfactant (Pluronic F127) were added and when it was dissolved, water was added to create an emulsion. The $\mathrm{H}_{2} \mathrm{O}: \mathrm{Al}$ molar ratios studied were 2:1, 11:1 and 20:1, with $8.8,48.5$ and $88 \mathrm{~mL}$ of distilled $\mathrm{H}_{2} \mathrm{O}$ added in each case, respectively. An additional $15 \mathrm{~mL}$ and $13 \mathrm{~mL}$ of ethanol and propanol, respectively, were dissolved. The mixture was allowed to age for approximately 22 hours at an ageing temperature of either $20{ }^{\circ} \mathrm{C}, 50{ }^{\circ} \mathrm{C}$ or $80{ }^{\circ} \mathrm{C}$. Then it was vacuum filtered to remove most of the solvents, obtaining a wet paste. Afterwards it was dried and calcined in a muffle furnace with flowing air with the following temperature dwells: $150{ }^{\circ} \mathrm{C}$ for $1 \mathrm{hr}, 350{ }^{\circ} \mathrm{C}$ for $2 \mathrm{hr}$ and finally $550{ }^{\circ} \mathrm{C}$ during $4 \mathrm{hr}$. The temperature ramps during the drying and calcination steps used were $1,5.5$ and $10{ }^{\circ} \mathrm{C} \cdot \mathrm{min}^{-1}$.

\subsection{Catalyst characterisation techniques}

The textural properties were measured by $\mathrm{N}_{2}$ adsorption at $77 \mathrm{~K}$ in a Micromeritics Tristar apparatus. The specific surface areas and pore volumes were calculated by applying the BET method to the respective $\mathrm{N}_{2}$ adsorption isotherms and the average pore diameter and the pore size distribution were calculated with the BJH method based on the adsorption-desorption branch of the $\mathrm{N}_{2}$ isotherm. 
Transmission Electron Microscopy (TEM) was carried out on a Jeol 2011 microscope equipped with $\mathrm{a} \mathrm{LaB}_{6}$ gun and operating at $200 \mathrm{kV}$. The samples were firstly finely grounded, dispersed in ethanol and a drop of solution was then deposited on a classical TEM copper grid, previously covered by a lacey amorphous carbon film. Examination of the sample was focused on parts of the samples lying across the holes to obtain information free from the contribution of the supporting carbon film.

Powder X-ray diffraction (XRD) patterns of OMA were acquired in a PANalytical diffractometer equipped with a Ni-filtered $\mathrm{Cu} \mathrm{K} \alpha(\lambda: 0.154 \mathrm{~nm})$ and a secondary graphite monochromator, using a $\theta-2 \theta$ configuration. Low angle diffraction with a $2 \theta$ range of $0.8-3^{\circ}$ was performed. Counts were accumulated every $0.01^{\circ}$ and the step time was $3 \mathrm{~s}$. Wide angle scans were performed at a $2 \theta$ range of $10-80^{\circ}$, step of $0.01^{\circ}$ and step time $5 \mathrm{~s}$.

\subsection{Experimental design and statistical analysis}

The study of the quantitative influence of the alumina synthesis conditions $\left(\mathrm{H}_{2} \mathrm{O}: \mathrm{Al}\right.$, $\left.\mathrm{T}_{\mathrm{ag}}, \mathrm{r}_{\mathrm{cal}}\right)$ on the alumina textural properties $\left(\mathrm{S}_{\mathrm{BET}}, \mathrm{V}_{\mathrm{p}}\right.$ and $\left.\mathrm{APD}\right)$ was carried out using an experimental design. This method is appropriate to study the influence of the experimental variables on the textural properties by applying an empirical modelling technique. Additionally, it is possible to evaluate the interaction between the different synthesis conditions, reducing the number of experiments and optimising resources and time [17]. Firstly, a full factorial design with 3 factors, named $\mathrm{H}_{2} \mathrm{O}: \mathrm{Al}$ ratio $\left(\mathrm{X}_{\mathrm{WA}}\right)$, ageing temperature $\left(\mathrm{X}_{\mathrm{T}}\right)$ and calcination heating rate $\left(\mathrm{X}_{\mathrm{R}}\right)$, and two levels $(+1$ and -1$)$ was carried out. The specific surface area $\left(\mathrm{Y}_{\mathrm{S}}\right)$, the pore volume $\left(\mathrm{Y}_{\mathrm{V}}\right)$ and the average 
pore diameter $\left(\mathrm{Y}_{\mathrm{D}}\right)$ were the studied response variables since they are among the most important textural properties of catalytic supports. The selection of levels of the different factors was carried out on the basis of results obtained previously by other groups, as reviewed in [1]. This work is aimed at studying a wide range of values in order to obtain a high heterogeneity in the textural properties of the prepared aluminas. Therefore, $\mathrm{H}_{2} \mathrm{O}: \mathrm{Al}$ ratio was varied between 2:1 (level -1) and 20:1 (level +1 ), the ageing temperature was modified between 20 (level -1) and $80^{\circ} \mathrm{C}($ level +1$)$ and finally, the calcination heating rate was studied between 1 (level -1$)$ and $10^{\circ} \mathrm{C} \cdot \mathrm{min}^{-1}($ level +1$)$. Samples 1-8 are within these variable values.

In order to analyse inherent variability, three repetitions of the central point were added to the design (samples 9-11). Due to significant curvature obtained after the full factorial design $2^{3}$, additional experiments were carried out to augment the model following a Box-Wilson Central Composite Design Face Centred (CCF, $\alpha: \pm 1)$ (samples 12-17). In this work, only results obtained with the Box-Wilson CCF model are included. The experimental augmented matrix is presented in Table 1. The textural properties of OMA are also included.

The significance of each model term was determined by means of ANOVA analyses and using the mathematical software Design Expert 7.0.0 (State-Ease Inc). A model term is more significant when its coefficient estimate is larger and its p-value smaller. The factors that significantly affect each textural property were determined using a confidence level of $95 \%\left(\mathrm{p}_{\text {value }} \leq 0.05\right)$. 


\section{Results and discussion}

\subsection{Influence of the preparation variables on the textural properties using statistical analysis}

As previously mentioned, Table 1 shows the experimental synthesis conditions used to prepare the materials under study and the results derived from the $\mathrm{N}_{2}$ adsorption characterization: $S_{\mathrm{BET}}, \mathrm{V}_{\mathrm{p}}$ and APD. It can be observed that the synthesised OMA provided a wide range of textural parameters, with $S_{\mathrm{BET}}, \mathrm{V}_{\mathrm{p}}$ and APD ranging from 298.7 to $393.1 \mathrm{~m}^{2} \cdot \mathrm{g}^{-1}$, from 0.935 to $1.678 \mathrm{~cm}^{3} \cdot \mathrm{g}^{-1}$ and from 8.1 to $17.9 \mathrm{~nm}$, respectively. APD values obtained in this work are significant larger than those reviewed in [1] using the non-ionic templating method. $S_{\mathrm{BET}}$ and $\mathrm{V}_{\mathrm{p}}$ were in the range of values reported despite the significant variations in the conditions and materials used for the synthesis.

A quadratic model (1) was used to evaluate the effect of the synthesis conditions ( $\mathrm{X}_{\mathrm{WA}}$, $\mathrm{X}_{\mathrm{T}}$ and $\left.\mathrm{X}_{\mathrm{R}}\right)$ in the three response variables $\left(\mathrm{Y}_{\mathrm{S}}, \mathrm{Y}_{\mathrm{V}}, \mathrm{Y}_{\mathrm{D}}\right)$ using a Box-Wilson $\mathrm{CCF}$ design. Model terms $\left(\mathrm{X}_{\mathrm{WA}}, \mathrm{X}_{\mathrm{T}}, \mathrm{X}_{\mathrm{R}}\right.$, and theirs interaction factors) are included in the quadratic model as coded factors $(-1 /+1)$.

$Y=a_{0}+a_{1} X_{W A}+a_{\mathbf{z}} X_{T}+a_{\mathbf{3}} X_{R}+a_{1 \mathbf{z}} X_{W A} X_{T}+a_{1 \mathbf{a}} X_{W A} X_{R}+a_{2 \mathrm{a}} X_{T} X_{R}+a_{1 \mathbf{1}} X_{W A}^{2}+a_{2 \mathbf{z}} X_{T}^{2}+a_{3 \mathbf{3}} X_{R}^{2}$

\subsubsection{Specific surface area}

In Table 2, only the model terms that significantly affected $\mathrm{Y}_{\mathrm{S}}$ are included together with their respective coefficient estimate, standard error and p-value. For the experimental range of factors studied, the most significant model term was $\mathrm{X}_{\mathrm{WA}}$. Additionally, some interaction factors as $\mathrm{X}_{\mathrm{WA}} \cdot \mathrm{X}_{\mathrm{T}}$ and $\mathrm{X}_{\mathrm{T}} \cdot \mathrm{X}_{\mathrm{R}}$ also affected $\mathrm{Y}_{\mathrm{S}}$ 
significantly. The adjustment of the experimental data to the quadratic model (which uses coded factors) resulted in the equation (2) $\left(\mathrm{R}^{2}: 0.83\right)$.

$Y_{S}=333.7-21.49 \cdot X_{W A}-13.15 \cdot X_{W A} \cdot X_{T}+10.68 \cdot X_{T} \cdot X_{R}(2)$

Figure 1 shows the contour plots of the specific surface area $\left(\mathrm{Y}_{\mathrm{S}}\right)$ as a function of $\mathrm{X}_{\mathrm{T}}$ and $\mathrm{X}_{\mathrm{R}}$ at three different $\mathrm{X}_{\mathrm{WA}}$. The highest $\mathrm{Y}_{\mathrm{S}}$ values were obtained at the lowest $\mathrm{X}_{\mathrm{WA}}$ (Figure 1a) in the region where $X_{T}$ and $X_{R}$ took their highest values, $80{ }^{\circ} \mathrm{C}$ and 10 ${ }^{\circ} \mathrm{C} \cdot \mathrm{min}^{-1}$ respectively. These results are in total agreement with the experimental data since the highest $S_{\mathrm{BET}}$ was obtained for the alumina $5\left(393.1 \mathrm{~m}^{2} \cdot \mathrm{g}^{-1}\right)$, which was prepared under these synthesis conditions. The lowest $\mathrm{Y}_{\mathrm{S}}$ values were reached at the highest $\mathrm{X}_{\mathrm{WA}}$ (Figure 1c). However, in this case, the region corresponded to the highest values of $\mathrm{X}_{\mathrm{T}}$ and the lowest values of $\mathrm{X}_{\mathrm{R}}, 80{ }^{\circ} \mathrm{C}$ and $1{ }^{\circ} \mathrm{C} \cdot \mathrm{min}^{-1}$, respectively. OMA 7 prepared under these particular conditions showed one of the lowest $S_{\mathrm{BET}}$ measured $\left(312.7 \mathrm{~m}^{2} \cdot \mathrm{g}^{-1}\right)$.

Analyzing the effect of $X_{T}$ and $X_{R}$, it was observed that for the lowest $X_{W A}$ studied $\left(X_{\mathrm{WA}}: 2\right)$ (Figure 1a), $Y_{\mathrm{S}}$ increased as the $\mathrm{X}_{\mathrm{T}}$ did and finally reached its maximum value at the maximum values of $\mathrm{X}_{\mathrm{T}}$ and $\mathrm{X}_{\mathrm{R}}$, as previously commented. According to this model, $\mathrm{Y}_{\mathrm{S}}$ did not depend on $\mathrm{X}_{\mathrm{R}}$ at $\mathrm{X}_{\mathrm{T}}: 50{ }^{\circ} \mathrm{C}$, since a straight contour was observed. However, at $\mathrm{X}_{\mathrm{T}}$ lower than $50{ }^{\circ} \mathrm{C}$, a decrease of $\mathrm{Y}_{\mathrm{s}}$ is observed as $\mathrm{X}_{\mathrm{R}}$ increased. The opposite effect was observed above $50^{\circ} \mathrm{C}$.

Figure $1 \mathrm{~b}$ shows the contour plot of $\mathrm{Y}_{\mathrm{S}}$ at the medium $\mathrm{X}_{\mathrm{WA}}\left(\mathrm{X}_{\mathrm{WA}}: 11\right)$. Due to the symmetry found in the results, the maximum values of $Y_{S}$ were reached at both the lowest and the highest values of $X_{T}$ and $X_{R}$. 
Finally, when $\mathrm{X}_{\mathrm{WA}}$ was increased up to 20 (Figure 1c), the opposite behaviour as respect to that in Figure 1a was observed. In this case, the maximum value of $\mathrm{Y}_{\mathrm{S}}$ was obtained at the lowest values of $X_{T}$ and $X_{R}$, and as $X_{T}$ increased, a decrease in $Y_{S}$ was observed.

In summary, a wide range of $\mathrm{Y}_{\mathrm{S}}$ values were obtained depending on the alumina preparation conditions. The $\mathrm{Y}_{\mathrm{s}}$ ranged approximately between 300 and $400 \mathrm{~m}^{2} \cdot \mathrm{g}^{-1}$ and the most influential variable was $\mathrm{X}_{\mathrm{WA}}$. Ys was found to increase as $\mathrm{X}_{\mathrm{WA}}$ decreased. However, both $X_{T}$ and $X_{R}$ affected slightly the $Y_{S}$ for a given $X_{W A}$.

\subsubsection{Pore Volume}

The model terms that significantly affected $\mathrm{Y}_{\mathrm{V}}$ are listed in Table 3 together with its coefficient estimate, standard error and p-value. In this case, the most significant model term was $\mathrm{X}_{\mathrm{WA}}^{2}$, followed by $\mathrm{X}_{\mathrm{WA}}$ and $\mathrm{X}_{\mathrm{T}} \cdot \mathrm{X}_{\mathrm{R}}$. The adjustment of the experimental data to the model resulted in equation $(3)\left(\mathrm{R}^{2}: 0.84\right)$.

$Y_{W}=1.520+0.16 \cdot X_{W A}+0.096 \cdot X_{T} \cdot X_{R}-0.33 \cdot X_{W A}^{2}(3)$

In Figure 2, $Y_{V}$ is represented as a function of the $X_{W A}$ at the medium $X_{T}$ and $X_{R}$ (the same trend was observed regardless the values of $X_{T}$ and $X_{R}$ ). Curvature was well appreciated and the maximum value of $\mathrm{Y}_{\mathrm{V}}$ was obtained at approximately the intermediate $\mathrm{X}_{\mathrm{WA}}\left(\mathrm{X}_{\mathrm{WA}} \approx 11\right)$. Besides this, the minimum value of $\mathrm{Y}_{\mathrm{V}}$ was obtained at the lowest $\mathrm{X}_{\mathrm{WA}}\left(\mathrm{X}_{\mathrm{WA}}: 2\right)$ and a medium value of $\mathrm{Y}_{\mathrm{V}}$ was obtained at the highest $\mathrm{X}_{\mathrm{WA}}$ $\left(\mathrm{X}_{\mathrm{WA}}: 20\right)$.

Despite the clear effect of $X_{W A}$ on $Y_{V}$, the effect of the interaction term $X_{T} \cdot X_{R}$ has to be taken into account and it is represented in Figure 3 at three different $\mathrm{X}_{\mathrm{WA}}$. The same trend as in Figure 2 was observed. When $X_{\mathrm{WA}}: 2$ (Figure $3 \mathrm{a}$ ), $\mathrm{Y}_{\mathrm{V}}$ had the lowest values, 
ranging from 0.961 to $1.089 \mathrm{~cm}^{3} \cdot \mathrm{g}^{-1}$. When the value of $\mathrm{X}_{\mathrm{WA}}$ was increased to 11 (Figure $3 b), Y_{V}$ reached the maximum values $\left(1.451-1.580 \mathrm{~cm}^{3} \cdot \mathrm{g}^{-1}\right)$. Finally, when $\mathrm{X}_{\mathrm{WA}}$ : 20 (Figure 3c), Yv values slightly decreased to $1.289-1.417 \mathrm{~cm}^{3} \cdot \mathrm{g}^{-1}$. In all cases, a symmetric trend was detected, observing two maxima and two minima in values of $\mathrm{Y}_{\mathrm{V}}$ for each $\mathrm{X}_{\mathrm{WA}}$. These points were located on opposite corners. The maximum values of $Y_{V}$ were observed when both $X_{R}$ and $X_{T}$ were in the same level $(+1$ or -1$)$ and the minima were observed when they were in different levels. For example, in Figure 3a, when $\mathrm{X}_{\mathrm{T}}$ was $80^{\circ} \mathrm{C}($ level +1$)$ and $\mathrm{X}_{\mathrm{R}}$ was $10{ }^{\circ} \mathrm{C} \cdot \mathrm{min}^{-1}($ level +1$)$ a maximum value of $\mathrm{Y}_{\mathrm{v}}$ was reached. However, for $\mathrm{X}_{\mathrm{T}}: 80^{\circ} \mathrm{C}($ level +1$)$ and $\mathrm{X}_{\mathrm{R}}: 1^{\circ} \mathrm{C} \cdot \mathrm{min}^{-1}($ level -1$)$, a minimum value was obtained.

\subsubsection{Average pore diameter}

$\mathrm{Y}_{\mathrm{D}}$ was strongly influenced by $\mathrm{X}_{\mathrm{WA}}$. Both, $\mathrm{X}_{\mathrm{WA}}$ and $\mathrm{X}_{\mathrm{WA}}{ }^{2}$ significantly affected $\mathrm{Y}_{\mathrm{D}}$. Each model term along its coefficient estimate, standard error and p-value are presented in Table 4. In this case, interaction terms were found to be no significant (p-value > 0.05) and therefore have not been considered. The adjustment of the experimental data to the model resulted in equation (4) which only includes $X_{\mathrm{WA}}$ effects $\left(\mathrm{R}^{2}: 0.76\right)$.

$Y_{D}=16.4+2.57 \cdot X_{W A}-3.77 \cdot X_{W A}^{2}(4)$

In this case, only a one-factor figure is plotted since only $\mathrm{X}_{\mathrm{WA}}$ significantly affected $\mathrm{Y}_{\mathrm{D}}$. In Figure $4, Y_{D}$ is represented as a function of $X_{W A}$ at the medium $X_{R}$ and $X_{T}$ (the same trend was observed regardless of these synthesis conditions for the other $\mathrm{X}_{\mathrm{W}}$ studied). Again, a significant curvature was observed. According to the statistical model, the maximum values of $Y_{D}$ were reached at values slightly above the medium value of $X_{W A}$ $(\approx 14: 1)$. In addition, the model predicted that higher $Y_{D}$ values are obtained at high values of $X_{\mathrm{WA}}(20: 1)$ than at low values $(2: 1)$. 


\subsection{Textural and structural properties}

Four aluminas presenting well differentiated APD were selected to gain more insight into their textural and structural properties as well as their porous architecture. Thus, the characterization of OMA $3(8.1 \mathrm{~nm}), 2(11 \mathrm{~nm}), 10(15.5 \mathrm{~nm})$ and $5(17.9 \mathrm{~nm})$ by $\mathrm{N}_{2}$ adsorption, TEM and XRD is presented in the following section.

\subsection{1. $\mathrm{N}_{2}$ adsorption}

Figure 5 shows the $\mathrm{N}_{2}$ isotherms of the OMA under consideration. They presented specific surface area values in the range $339.8-374.2 \mathrm{~m}^{2} \cdot \mathrm{g}^{-1}$. Sample 3 presented the highest $\mathrm{S}_{\mathrm{BET}}$ among the four aluminas under consideration $\left(374.2 \mathrm{~m}^{2} \cdot \mathrm{g}^{-1}\right)$, followed by the alumina $5\left(353.5 \mathrm{~m}^{2} \cdot \mathrm{g}^{-1}\right)$. Aluminas 2 and 10 showed similar values (338.6 and $339.8 \mathrm{~m}^{2} \cdot \mathrm{g}^{-1}$, respectively), being the lowest values in $\mathrm{S}_{\mathrm{BET}}$ among all 4 samples under study.

$\mathrm{N}_{2}$ adsorption-desorption isotherms showed a relatively steep increase in the adsorbed amount starting at $\mathrm{P} / \mathrm{P}_{\mathrm{o}}$ about 0.6-0.8. Sample 3 presented a type IV isotherm, which corresponds to a mesoporous material, and a hysteresis of type $\mathrm{H} 1$, typically assigned to capillary condensation taking place in mesopores [18]. The isotherm ended with a nearly horizontal plateau indicating a relative narrow pore size distribution (PSD), as discussed below. On the other hand, aluminas 2, 10 and 5 showed a $\mathrm{N}_{2}$ adsorptiondesorption isotherms of type IV with a $\mathrm{H} 3$ hysteresis loop, which can be assigned to crystalline metal oxide aggregates of slit-like shape [18]. The adsorption at high $\mathrm{P} / \mathrm{P}_{\mathrm{o}}$ pointed out at the presence of a larger pore size and a wider PSD as compared to the alumina 3. A transition in the shape of the isotherms between the samples 3 and 5 was observed. This fact is related to the differences in PSD, as observed in the inset on Figure 5. Sample 3 showed a narrow PSD centred around $8 \mathrm{~nm}$, as it was anticipated 
from the plateau in the isotherm. The maximum in the PSD for the alumina 2 was also centred at ca. $8 \mathrm{~nm}$, although the appearance of wider pores shifted the APD towards higher values $(11 \mathrm{~nm})$. Aluminas 10 and 5 presented similar PSD curves centred at ca. $17 \mathrm{~nm}$, although sample 5 presented a larger fraction of larger pores than alumina 10. This promoted a shift of the APD to larger values as compared to the alumina 10 (from $15.5 \mathrm{~nm}$ to $17.9 \mathrm{~nm})$, similar to what happened with alumina 2.

\subsubsection{TEM study}

A TEM study was carried out in order to elucidate the differences in the structure and pore architecture of the prepared OMA. Thus, Figure 6 shows two micrographs at different magnifications $(10,000 \mathrm{X}$ and $100,000 \mathrm{X})$ for each of the four aluminas under study. The low magnification TEM image of sample 3 (Figure 6a) shows a typical worm-like motif, typically observed for self-assembled aluminas using the surfactant templating method $[6,19]$. The packing of the channel system appeared to be random, therefore indicating the non-existence of long-range channel packing order. Figure $6 \mathrm{~b}$ shows that alumina 3 was formed by an intricate mixture of short corrugated platelets as previously reported by other authors $[12,15]$. Some of these platelets adopted a rounded morphology, thus providing the relative narrow PSD observed from the $\mathrm{N}_{2}$ adsorption study (Figure 5).

The worm like motif was fairly retained in the OMA 2 (Figure 6c), although high magnification (Figure 6d) provided evidence of the enlargement of the platelets when compared to sample 3. This fact was more discernible as the APD of the OMA increased. For instance, in the low magnification TEM images of aluminas 10 and 5 (Figures 6e and 6g, respectively) the edge of the platelets could clearly be observed forming slit-shaped mesopores. On the other hand, the high magnification micrograph 
of sample 10 (Figure 6f) confirmed the presence of long straight platelets of ca. 20-40 $\mathrm{nm}$ length. Figure 6h (high magnification micrograph of alumina 5) shows the presence of platelets of ca. $60-80 \mathrm{~nm}$ long.

Thus, it can be concluded that the APD increased as the platelets became larger and less rounded, giving rise to a wider pore size distribution. No discernible pattern regarding the wall thickness of the platelets, taking values in the $2-3 \mathrm{~nm}$ range, could be inferred from the TEM study. As the platelets became larger, a transition between a wormlike motif to lamellar or slit-like was observed, as previously reported in [9]. This observation confirms the interpretation of the $\mathrm{N}_{2}$ adsorption-desorption isotherms shown in Figure 5, in which two well-differentiated shapes were observed.

As further discussed below, $\mathrm{H}_{2} \mathrm{O}: \mathrm{Al}$ ratio played an important role in the length of the platelets. Thus, this TEM study revealed that larger and more lamellar platelets were obtained at medium (11:1) and high (20:1) $\mathrm{H}_{2} \mathrm{O}: \mathrm{Al}$ ratios (samples 10 and 5, respectively), therefore explaining the difference in APD observed.

\subsubsection{XRD study}

Figure 7a shows the wide angle XRD diffractograms of the studied aluminas. Samples 2 and 3 showed no diffraction lines characteristic of an ordered oxide phase, which is indicative of mesostructure with amorphous framework walls [9]. Three broad, low intensity peaks that are typically assigned to gamma alumina $\left(38^{\circ}, 46^{\circ}\right.$ and $\left.67^{\circ}\right)$ were observed in the aluminas with wider pore size distribution (5 and 10). This suggests the appearance of some degree of ordering, although the framework walls can still be considered amorphous due to the poor reflection obtained. The slight differences in crystallinity may be related to the $\mathrm{H}_{2} \mathrm{O}$ : $\mathrm{Al}$ ratio used. It was reported $[12,20,21]$ that a high $\mathrm{H}_{2} \mathrm{O}$ :Al ratio strongly influences the aluminium phases in the final products, 
leading to more crystalline materials. In this case, aluminas 5 and 10 were prepared with $\mathrm{H}_{2} \mathrm{O}: \mathrm{Al}$ ratios of 11 and 20, respectively, as compared to the hydrolysis ratio of 2 used to synthesise the aluminas 2 and 3.

Small angle XRD diffractograms are shown in Figure $7 \mathrm{~b}$. The absence of broad reflections in the small angle region near $2^{\circ}$ indicates the irregularity in the separation between single channels [6]. However, the TEM study revealed that alumina 3 showed a worm like pore packing in which, to some extent, uniformity between pores can be inferred (Figure 6a). In fact, several examples of similar worm-like structures, which present characteristic reflections at low angles, can be found in the literature $[6,9,19$, 22]. This apparent discrepancy in the results of this work can be tentatively explained attending to the larger APD shown by OMA used in this work, as compared to the related structures reported in the studies previously mentioned. This causes a shift in the expected broad reflection to $2 \theta$ value lower than $1^{\circ}$, where X-ray diffraction cannot be measured with sufficient accuracy. Similar low angle XRD plots for aluminas showing wide pores (higher than $8 \mathrm{~nm}$ ) as those found in this work can be found in [21].

\section{Discussion}

The non ionic templating method using Pluronic F127 as surfactant and aluminum isopropanoxide as aluminum source was used to prepare a number of aluminas varying the synthesis conditions. A Box-Wilson Central Composite Design Face Centred (CCF, $\alpha: \pm 1)$ was used to model the influence of the synthesis conditions on the textural properties of the as prepared OMA. 
Some differences were observed comparing $\mathrm{Y}_{\mathrm{S}}, \mathrm{Y}_{\mathrm{V}}$ and $\mathrm{Y}_{\mathrm{D}}$ models. In all cases, the model showed a strong dependence on model term $\mathrm{X}_{\mathrm{WA}}\left(\right.$ or $\mathrm{X}_{\mathrm{WA}}{ }^{2}$ ). In the case of $\mathrm{Y}_{\mathrm{S}}$ and $Y_{V}$ models (equations 2 and 3, respectively), the influence of $X_{T}$ and $X_{R}$ interaction was significant since they modified the response values. In addition, the quadratic term $\left(\mathrm{X}_{\mathrm{WA}}{ }^{2}\right)$ contributed significantly to the model curvature of $\mathrm{Y}_{\mathrm{V}}$ and $\mathrm{Y}_{\mathrm{D}}$ models. This led to the presence of two maximum and two minimum values of the corresponding response variables in the contour plots (Figure 3 for $Y_{V}$, figure not included for $\mathrm{Y}_{\mathrm{D}}$ ), regardless the value of $\mathrm{X}_{\mathrm{WA}}(2: 1,11: 1$ or $20: 1)$. Furthermore, the effect of $\mathrm{X}_{\mathrm{WA}}$ on the $\mathrm{Y}_{\mathrm{V}}$ and $\mathrm{Y}_{\mathrm{D}}$ models was very similar.

Therefore, $\mathrm{H}_{2} \mathrm{O}$ : Al can be considered as the most determinant synthesis variable since it is the only term that appeared (as $\mathrm{X}_{\mathrm{WA}}, \mathrm{X}_{\mathrm{WA}}{ }^{2}$ and/or $\mathrm{X}_{\mathrm{WA}} \cdot \mathrm{X}_{\mathrm{T}}$ ) in the three models (equations 2-4) obtained. Characterisation data shown in Section 3.2. revealed the paramount effect of $\mathrm{H}_{2} \mathrm{O}: \mathrm{Al}$ on the OMA structure. The TEM study showed that larger and more lamellar platelets were obtained at medium (11:1) and high (20:1) $\mathrm{H}_{2} \mathrm{O}: \mathrm{Al}$ ratios (samples 10 and 5, respectively), resulting in marked variations in the APD, as $\mathrm{N}_{2}$ adsorption study showed. The analysis of data in Table 1 revealed a clear trend for $\mathrm{V}_{\mathrm{p}}$ and APD as a function of the $\mathrm{H}_{2} \mathrm{O}: \mathrm{Al}$ ratio. Thus, the highest values of $\mathrm{V}_{\mathrm{p}}$ and APD were mainly obtained at medium $(11: 1) \mathrm{H}_{2} \mathrm{O}: \mathrm{Al}$ ratio, and in less extent at high (20:1) ratio. However, no clear trend can be observed between $\mathrm{H}_{2} \mathrm{O}$ :Al ratio and $\mathrm{S}_{\mathrm{BET}}$, despite the fact that highest $\mathrm{S}_{\mathrm{BET}}$ values were obtained at low $(2: 1) \mathrm{H}_{2} \mathrm{O}$ :Al ratio. This fact is probably due to the presence of two interaction factors $\left(\mathrm{X}_{\mathrm{WA}} \cdot \mathrm{X}_{\mathrm{T}}\right.$ and $\left.\mathrm{X}_{\mathrm{T}} \cdot \mathrm{X}_{\mathrm{R}}\right)$ in the $\mathrm{Y}_{\mathrm{S}}$ model (equation 2). The effect of $\mathrm{H}_{2} \mathrm{O}$ : $\mathrm{Al}$ ratio in the APD was previously addressed using the non-ionic templating method, while no clear relationship between $\mathrm{H}_{2} \mathrm{O}: \mathrm{Al}$ ratio and the $\mathrm{S}_{\mathrm{BET}}$ was reported [12], similarly to the results here reported. However, in 
this work a clear relationship between $\mathrm{H}_{2} \mathrm{O}$ : $\mathrm{Al}$ ratio and $\mathrm{V}_{\mathrm{p}}$ was found, as opposed to results published in [12].

$\mathrm{T}_{\mathrm{ag}}$ effect was found to be less important than $\mathrm{H}_{2} \mathrm{O}: \mathrm{Al}$ ratio. No significant effects were detected for the single $X_{T}$ factor in the equations presented in section 3.1. However, interactions factors including $\mathrm{T}_{\mathrm{ag}}$ effect appeared as $\mathrm{X}_{\mathrm{WA}} \cdot \mathrm{X}_{\mathrm{T}}$ and $\mathrm{X}_{\mathrm{T}} \cdot \mathrm{X}_{\mathrm{R}}$ in the $\mathrm{Y}_{\mathrm{S}}$ model and as $\mathrm{X}_{\mathrm{T}} \cdot \mathrm{X}_{\mathrm{R}}$ in $\mathrm{Y}_{\mathrm{V}}$ equation. Neither the single factor $\left(\mathrm{X}_{\mathrm{T}}\right)$ nor the interaction factor involving $\mathrm{T}_{\mathrm{ag}}$ were included on the $\mathrm{Y}_{\mathrm{D}}$ equation. Since the single factor $\left(\mathrm{X}_{\mathrm{T}}\right)$ was not significant ( $\mathrm{p}$-value $>0.05$ ) for any textural property and the $\mathrm{T}_{\mathrm{ag}}$ effect was influenced by other factors, no obvious trend as a function of $\mathrm{T}_{\mathrm{ag}}$ can be inferred from data in Table 1. However, a decrease of the $\mathrm{V}_{\mathrm{p}}$ and APD as $\mathrm{T}_{\mathrm{ag}}$ increased was reported [7, 9]. In our case, $V_{p}$ was influenced by $T_{a g}$ but its effect depended on the heating temperature rate value due to the interaction factor $\left(\mathrm{X}_{\mathrm{T}} \cdot \mathrm{X}_{\mathrm{R}}\right)$ included in the $\mathrm{Y}_{\mathrm{V}}$ equation, while no significant influence of the $\mathrm{T}_{\mathrm{ag}}$ on the APD was observed.

The influence of the variation of $r_{\text {cal }}$ in the textural properties of OMA prepared by the non ionic templating method has received little attention. High $r_{\text {cal }}$ may cause structure collapse since surfactant combustion is highly endothermic [1]. A $r_{\text {cal }}$ lower than $5^{\circ} \mathrm{C} \cdot \min ^{-1}$ is commonly used, as reviewed in [1]. In this work, $r_{c a l}$ appeared as an interaction factor $\left(\mathrm{X}_{\mathrm{T}} \cdot \mathrm{X}_{\mathrm{R}}\right)$ in $\mathrm{Y}_{\mathrm{S}}$ and $\mathrm{Y}_{\mathrm{V}}$ models. $\mathrm{r}_{\mathrm{cal}}$ effect was found to be less significant than $\mathrm{H}_{2} \mathrm{O}: \mathrm{Al}$ ratio effect, and no clear trend was observed for any textural property. However, it is worth mentioning that high values of $S_{\text {BET }}\left(393.1 \mathrm{~m}^{2} \cdot \mathrm{g}^{-1}\right.$, OMA 4), $V_{p}\left(1.574 \mathrm{~cm}^{3} \cdot \mathrm{g}^{-1}\right.$, OMA 15) and APD (17.2 nm, OMA 15) were obtained when using a $\mathrm{r}_{\mathrm{cal}}$ of $10^{\circ} \mathrm{C} \cdot \mathrm{min}^{-1}$, providing evidence that no structure collapse occurred when high calcination heating rates were used. 


\section{Conclusions}

A number of OMA were prepared using the non-ionic templating method and a triblock co-polymer as structure directing agent. An experimental design based on a BoxWilson Central Composite Design Face Centred (CCF, $\alpha: \pm 1)$ was employed to study the effect of some synthesis conditions $\left(\mathrm{H}_{2} \mathrm{O}: \mathrm{Al}, \mathrm{T}_{\mathrm{ag}}\right.$ and $\left.\mathrm{r}_{\text {cal }}\right)$ on the resulting OMA textural properties $\left(\mathrm{S}_{\mathrm{BET}}, \mathrm{V}_{\mathrm{p}} \mathrm{APD}\right)$. The models obtained provided a satisfactory adjustment of the experimental data. $\mathrm{H}_{2} \mathrm{O}: \mathrm{Al}$ was found to be the most determinant synthesis variable since it influenced significantly $\mathrm{S}_{\mathrm{BET}}, \mathrm{V}_{\mathrm{p}}$ and APD. No significant effects were detected for the single $\mathrm{T}_{\mathrm{ag}}$ or $\mathrm{r}_{\mathrm{cal}}$ terms. However, interactions factors including these terms modified $S_{\mathrm{BET}}$ and $\mathrm{V}_{\mathrm{p}}$ values. Characterization of some representative OMA showed the formation of platelets of different length upon the synthesis conditions, giving rise to different pore size distributions. The statistical analysis carried out in this work provided useful information that allows the tailored synthesis of OMA with well differentiated textural properties.

\section{Acknowledgements}

S.d.LL. thanks the Diputación General de Aragón (Spain) for his PhD grant and CSIC for the funding of the short stay at Imperial College (project I-LINK ref.0439). H.P. thanks the support of CONACYT Mexico for the award of her PhD grant. J.L.P. thanks the Spanish MEC for a personal grant (Spanish Scientists Mobility Program, ref. EX2009-0822). Funds provided by FEDER and the Spanish Ministery of Economy and Competitiviness (Project ENE2011-28318-C03-01) are also acknowledged. 


\section{References}

[1] C. Márquez Alvarez, N. Zilkova, J. Pérez-Pariente, J. Čejka, Catal. Rev. 50 (2008) 222-286.

[2] C. Song, T. Nihonmatsu, M. Nomura, Ind. Eng. Chem. Res. 30 (1991) 1726-1734.

[3] J. Ancheyta, M.S. Rana, E. Furimsky, Catal. Today 109 (2005) 3-15.

[4] J. Čejka, Appl. Catal. A, Gen., 254 (2003) 327-338.

[5] S.A. Bagshaw, E. Prouzet, T.J. Pinnavaia, Science 269 (1995) 1242-1244.

[6] S.A. Bagshaw, T.J. Pinnavaia, Angew. Chem. Int. Edit. 35 (1996) 1102-1105.

[7] W. Deng, P. Bodart, M. Pruski, B.H. Shanks, Micropor. Mesopor. Mat. 52 (2002) 169-177.

[8] Z. Zhang, R.W. Hicks, T.R. Pauly, T.J. Pinnavaia, J. Am. Chem. Soc. 124 (2002) 1592-1593.

[9] Z. Zhang, T.J. Pinnavaia, J. Am. Chem. Soc. 124 (2002) 12294-12301.

[10] P. Yang, D. Zhao, D.I. Margolese, B.F. Chmelka, G.D. Stucky, Nature 396 (1998) 152-155.

[11] C. Boissière, L. Nicole, C. Gervais, F. Babonneau, M. Antonietti, H. Amenitsch, C. Sanchez, D. Grosso, Chem. Mat. 18 (2006) 5238-5243.

[12] C. Lesaint, W.R. Glomm, Ø. Borg, S. Eri, E. Rytter, G. Øye, Appl. Catal. A Gen. 351 (2008) 131-135.

[13] P. Alexandridis, L. Yang, Macromolecules 33 (2000) 5574-5587.

[14] W. Zhang, Chem. Commun. (1998) 1185-1186.

[15] - C. Márquez-Alvarez, E. Sastre, J. Pérez-Pariente, Micropor. Mesopor. Mat. 44-45 (2001) 203-210.

[16] M. Akia, S.M. Alavi, M. Rezaei, Z.-F. Yan, Micropor. Mesopor. Mat. 122 (2009) 72-78.

[17] G.E.P. Box, J.S. Hunter, W.G. Hunter, Statistics for Experimenters: Design, Innovation, and Discovery, Jhon Wiley \& Sons, New Jersey, 2005.

[18] K.S.W. Sing, D.H. Everett, R.A.W. Haul, L. Moscou, R.A. Pierotti, J. Rouquerol, T. Siemieniewska, Pure Appl. Chem. 57 (1985) 603-619.

[19] J. Čejka, P.J. Kooyman, L. Veselá, J. Rathouský, A. Zukal, Phys. Chem. Chem. Phys. 4 (2002) 4823-4829.

[20] Z. Shan, J.C. Jansen, W. Zhou, T. Maschmeyer, Appl. Catal. A Gen. 254 (2003) 339-343.

[21] H.C. Lee, H.J. Kim, C.H. Rhee, K.H. Lee, J.S. Lee, S.H. Chung, Micropor. Mesopor. Mat. 79 (2005) 61-68.

[22] R. Zhao, F. Guo, Y. Hu, H. Zhao, Micropor. Mesopor. Mat. 93 (2006) 212-216. 
Table 1. Summary of the synthesis conditions used and textural properties of the synthesized OMA.

\begin{tabular}{ccccccc}
\hline Sample & $\mathbf{H}_{\mathbf{2}} \mathbf{O}: \mathbf{A l}$ & $\mathbf{T}_{\mathbf{a g}}\left({ }^{\circ} \mathbf{C}\right)$ & $\mathbf{R}_{\mathbf{c a l}}\left({ }^{\circ} \mathbf{C} \cdot \mathbf{m i n}^{-\mathbf{1}}\right)$ & $\mathbf{S}_{\mathbf{B E T}}\left(\mathbf{m}^{\mathbf{2}} \cdot \mathbf{g}^{-\mathbf{1}}\right)$ & $\mathbf{V}_{\mathbf{p}}\left(\mathbf{c m}^{\mathbf{3}} \cdot \mathbf{g}^{\mathbf{- 1}}\right)$ & $\mathbf{A P D}^{*}(\mathbf{n m})$ \\
\hline 1 & 2 & 20 & 1 & 392.4 & 1.037 & 9.2 \\
2 & 2 & 20 & 10 & 338.6 & 0.935 & 11.0 \\
3 & 2 & 80 & 1 & 374.2 & 0.954 & 8.1 \\
4 & 2 & 80 & 10 & 393.1 & 1.051 & 9.2 \\
5 & 20 & 20 & 1 & 353.5 & 1.678 & 17.9 \\
6 & 20 & 20 & 10 & 341.2 & 1.215 & 12.0 \\
7 & 20 & 80 & 1 & 312.7 & 1.297 & 15.4 \\
8 & 20 & 80 & 10 & 313.1 & 1.406 & 16.0 \\
9 & 11 & 50 & 5.5 & 345.0 & 1.529 & 15.5 \\
10 & 11 & 50 & 5.5 & 339.8 & 1.501 & 15.5 \\
11 & 11 & 50 & 5.5 & 340.0 & 1.572 & 17.6 \\
\hline 12 & 2 & 50 & 5.5 & 335.7 & 1.18 & 12.1 \\
13 & 11 & 20 & 5.5 & 319.4 & 1.434 & 15.3 \\
14 & 11 & 50 & 1 & 314.2 & 1.566 & 17.7 \\
15 & 11 & 50 & 10 & 329.2 & 1.574 & 17.2 \\
16 & 11 & 80 & 5.5 & 310.4 & 1.421 & 16.1 \\
17 & 20 & 50 & 5.5 & 298.7 & 1.202 & 13.9 \\
\hline
\end{tabular}

*BJH model applied to the adsorption branch of the isotherms 
Table 2.

Specific surface area $\left(Y_{S}, m^{2} \cdot g^{-1}\right)$

Significant model

\begin{tabular}{|c|c|c|c|c|}
\hline Model term & $\begin{array}{c}\text { Coefficient estímate } \\
\left(\mathrm{m}^{2} \cdot \mathrm{g}^{-1}\right)\end{array}$ & $\begin{array}{c}\text { Standard error } \\
\left(\mathrm{m}^{2} \cdot \mathrm{g}^{-1}\right)\end{array}$ & $\begin{array}{c}\text { p-value } \\
(-)\end{array}$ & terms that fit the \\
\hline $\mathrm{X}_{\mathrm{WA}}$ & $-21,49$ & 2,97 & $<0,0001$ & evolution of the \\
\hline $\mathrm{X}_{\mathrm{WA}} \cdot \mathrm{X}_{\mathrm{T}}$ & $-13,15$ & 3,32 & 0,0022 & \\
\hline $\mathrm{X}_{\mathrm{T}} \cdot \mathrm{X}_{\mathrm{R}}$ & 10,68 & 3,32 & 0,0081 & specific surface \\
\hline
\end{tabular}

area by means of analysis of variance. 
Table 3. Significant model terms that fit the evolution of the pore volume by means of analysis of variance.

Pore volume $\left(\mathrm{Y}_{\mathrm{V}}, \mathrm{cm}^{3} \cdot \mathrm{g}^{-1}\right)$

\begin{tabular}{cccc}
\hline \hline Model term & $\begin{array}{c}\text { Coefficient estimate } \\
\left(\mathbf{c m}^{\mathbf{3}} \cdot \mathbf{g}^{-\mathbf{1}}\right)\end{array}$ & $\begin{array}{c}\text { Standard error } \\
\left(\mathbf{c m}^{\mathbf{3}} \cdot \mathbf{g}^{-\mathbf{1}}\right)\end{array}$ & $\begin{array}{c}\mathbf{p} \text {-value } \\
\mathbf{( - )}\end{array}$ \\
\hline $\mathrm{X}_{\mathrm{WA}}$ & 0,16 & 0,34 & 0,0004 \\
$\mathrm{X}_{\mathrm{T}} \cdot \mathrm{X}_{\mathrm{R}}$ & 0,096 & 0,038 & 0,027 \\
$\mathrm{X}_{\mathrm{WA}}{ }^{2}$ & $-0,33$ & 0,058 & 0,0001 \\
\hline
\end{tabular}


Table 4. Significant model terms that fit the evolution of the average pore diameter by means of analysis of variance.

Average pore diameter $\left(\mathbf{Y}_{\mathrm{D}}, \mathbf{n m}\right)$

\begin{tabular}{cccc}
\hline \hline Model term & $\begin{array}{c}\text { Coefficient estimate } \\
(\mathbf{n m})\end{array}$ & $\begin{array}{c}\text { Standard error } \\
(\mathbf{n m})\end{array}$ & $\begin{array}{c}\text { p-value } \\
(-)\end{array}$ \\
\hline $\mathrm{X}_{\mathrm{WA}}$ & 2,57 & 0,52 & 0,0003 \\
$\mathrm{X}_{\mathrm{WA}}{ }^{2}$ & $-3,77$ & 0,88 & 0,0009 \\
\hline
\end{tabular}




\section{FIGURE CAPTIONS}

Figure 1 Contour plots of $S_{B E T}$ as a function of $T_{a g}$ and $R_{\text {cal }}$ at three different $\mathrm{H}_{2} \mathrm{O}: \mathrm{Al}$ ratio: 2:1 (a), 11:1 (b) and 20:1 (c).

Figure 2. $\mathrm{V}_{\mathrm{p}}$ as a function of $\mathrm{H}_{2} \mathrm{O}: \mathrm{Al}$ ratio $\left(\mathrm{T}_{\mathrm{ag}}: 50^{\circ} \mathrm{C}\right.$ and $\left.\mathrm{R}_{\mathrm{cal}}: 5.5^{\circ} \mathrm{C} \cdot \mathrm{min}^{-1}\right)$

Figure 3. Contour plots of $\mathrm{V}_{\mathrm{p}}$ as a function of $\mathrm{T}_{\mathrm{ag}}$ and $\mathrm{R}_{\mathrm{cal}}$ at three different $\mathrm{H}_{2} \mathrm{O}: \mathrm{Al}$ ratio: 2:1 (a), 11:1 (b) and 20:1 (c).

Figure 4. $\mathrm{APD}$ as a function of $\mathrm{H}_{2} \mathrm{O}: \mathrm{Al}$ ratio $\left(\mathrm{T}_{\mathrm{ag}}: 50^{\circ} \mathrm{C}\right.$ and $\left.\mathrm{R}_{\mathrm{cal}}: 5.5^{\circ} \mathrm{C} \cdot \mathrm{min}^{-1}\right)$

Figure 5. $\mathrm{N}_{2}$ isotherm of OMA 2, 3, 5 and 10. Inset: pore size distribution calculated using desorption branches of the isotherm based on BJH model.

Figure 6. Low (10.000X) and high (100.000X) magnification TEM images of samples 3 (a and b), 2 (c and d), 10 (e and f) and 5 (g and h).

Figure 7. Wide angle (a) and low angle (b) difractograms of OMA 2, 3, 5 and 10. 
Figure 1
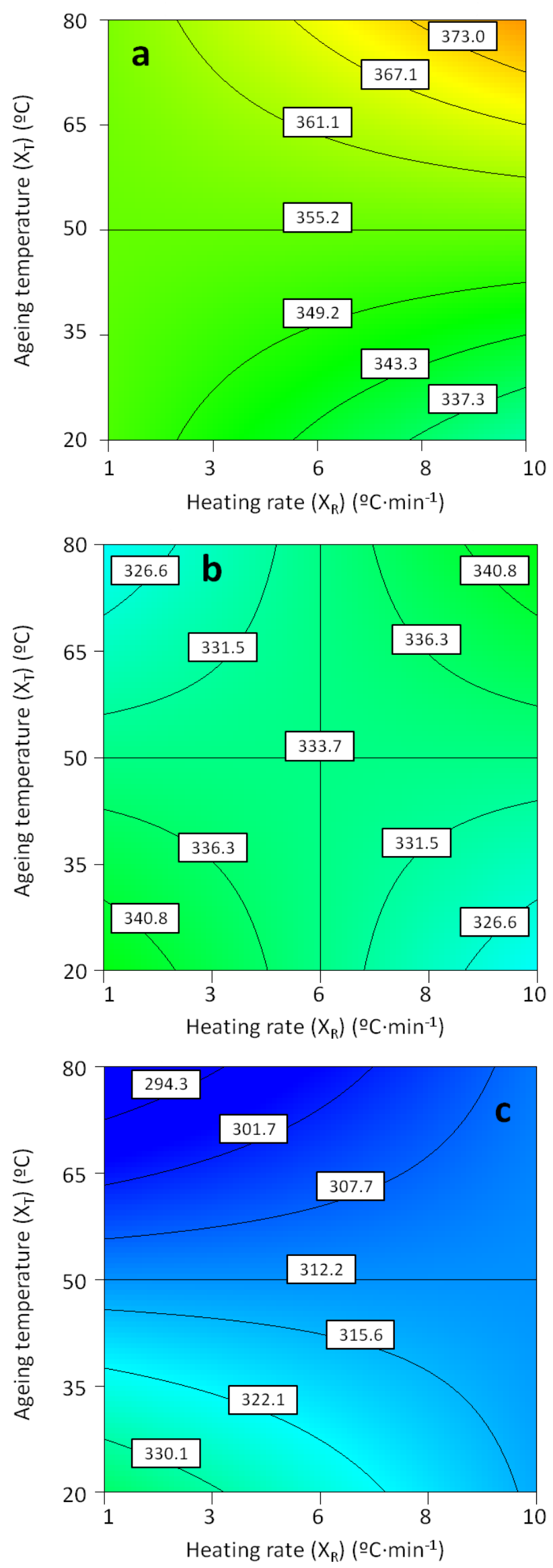
Figure 2

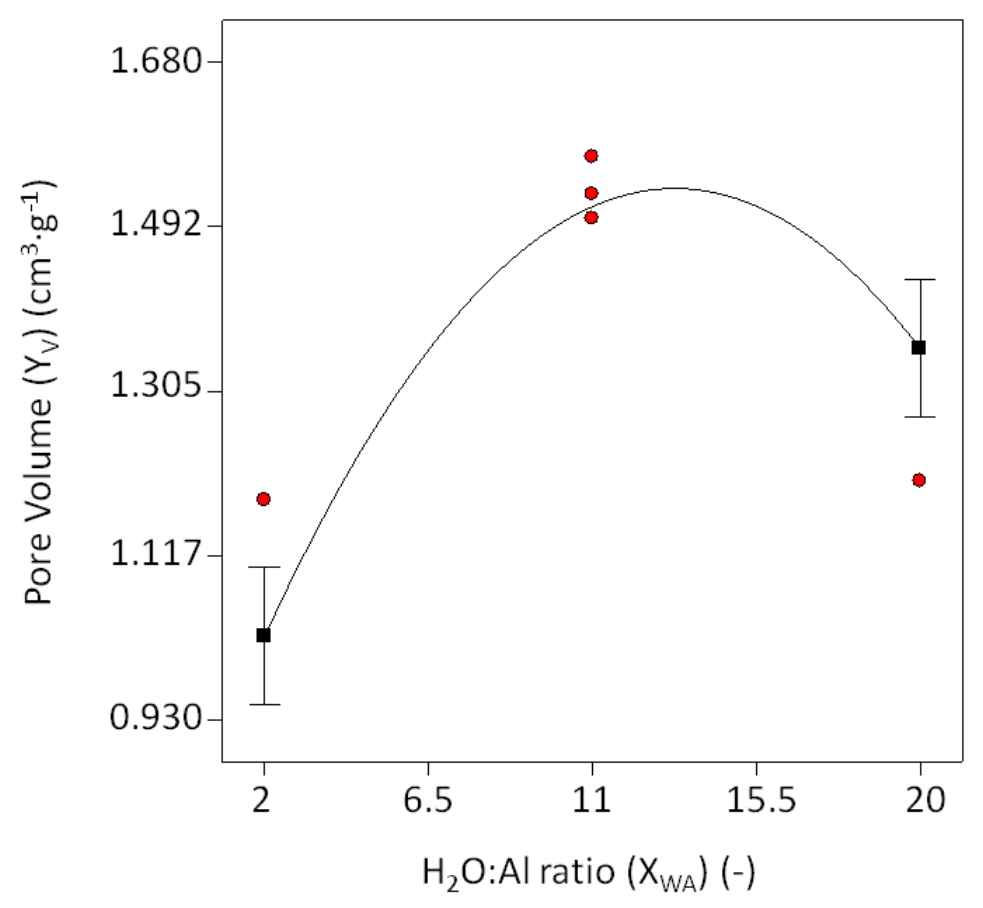


Figure 3
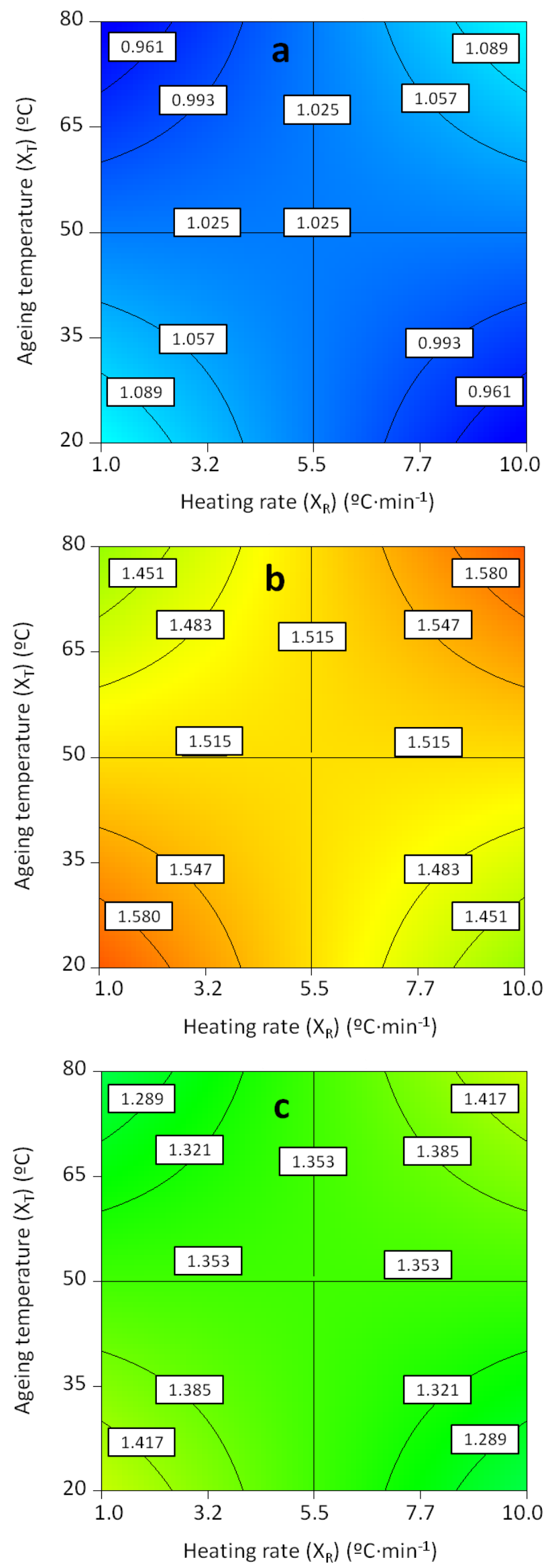
Figure 4

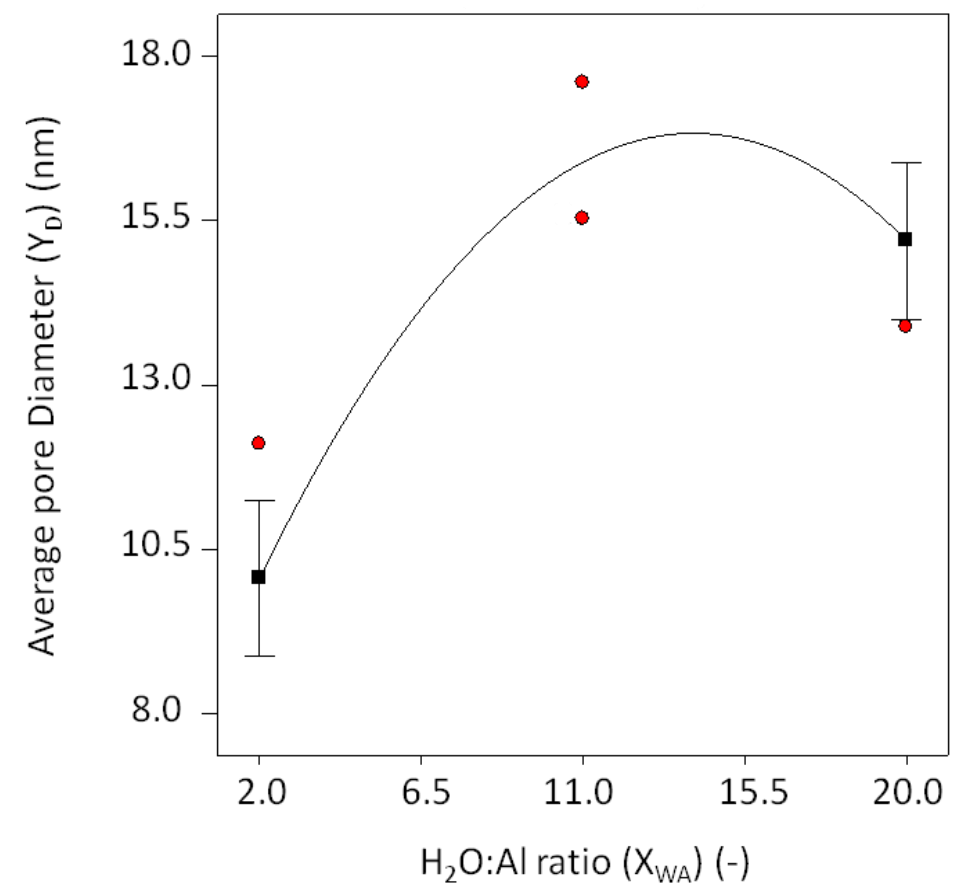


Figure 5

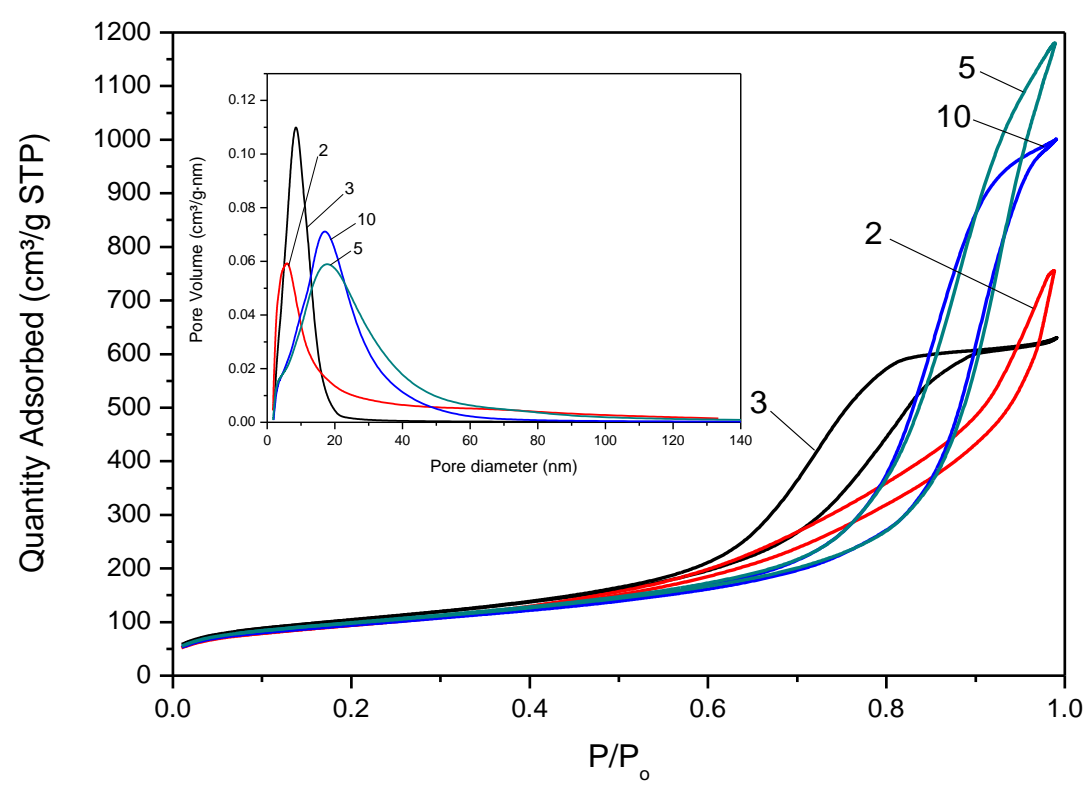


Figure 6
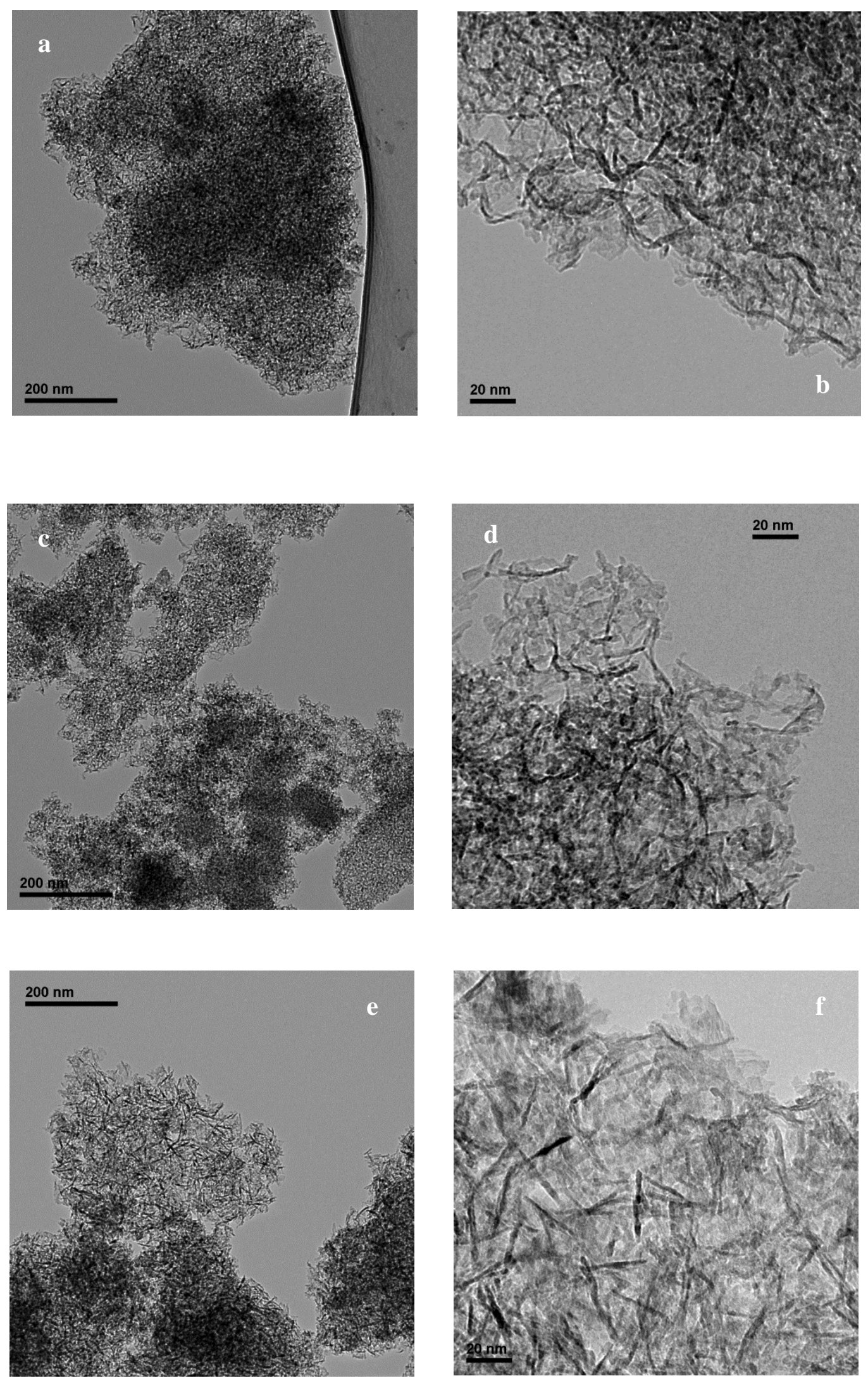

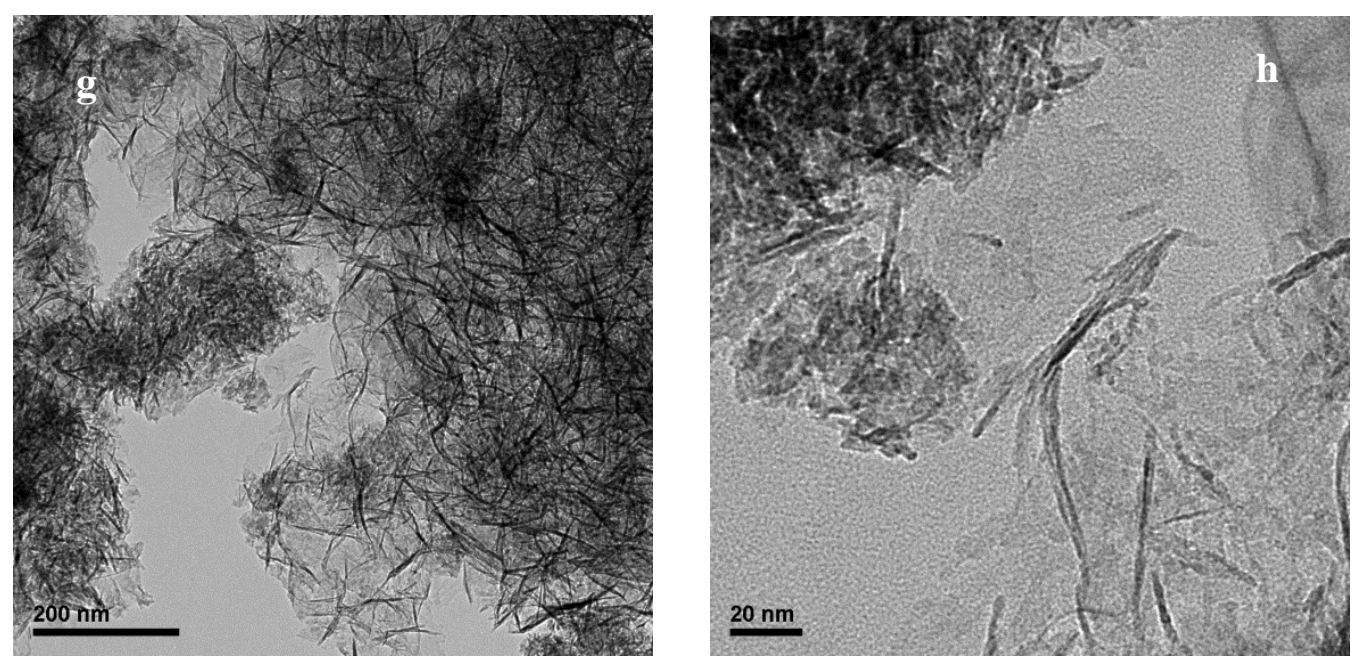
Figure 7
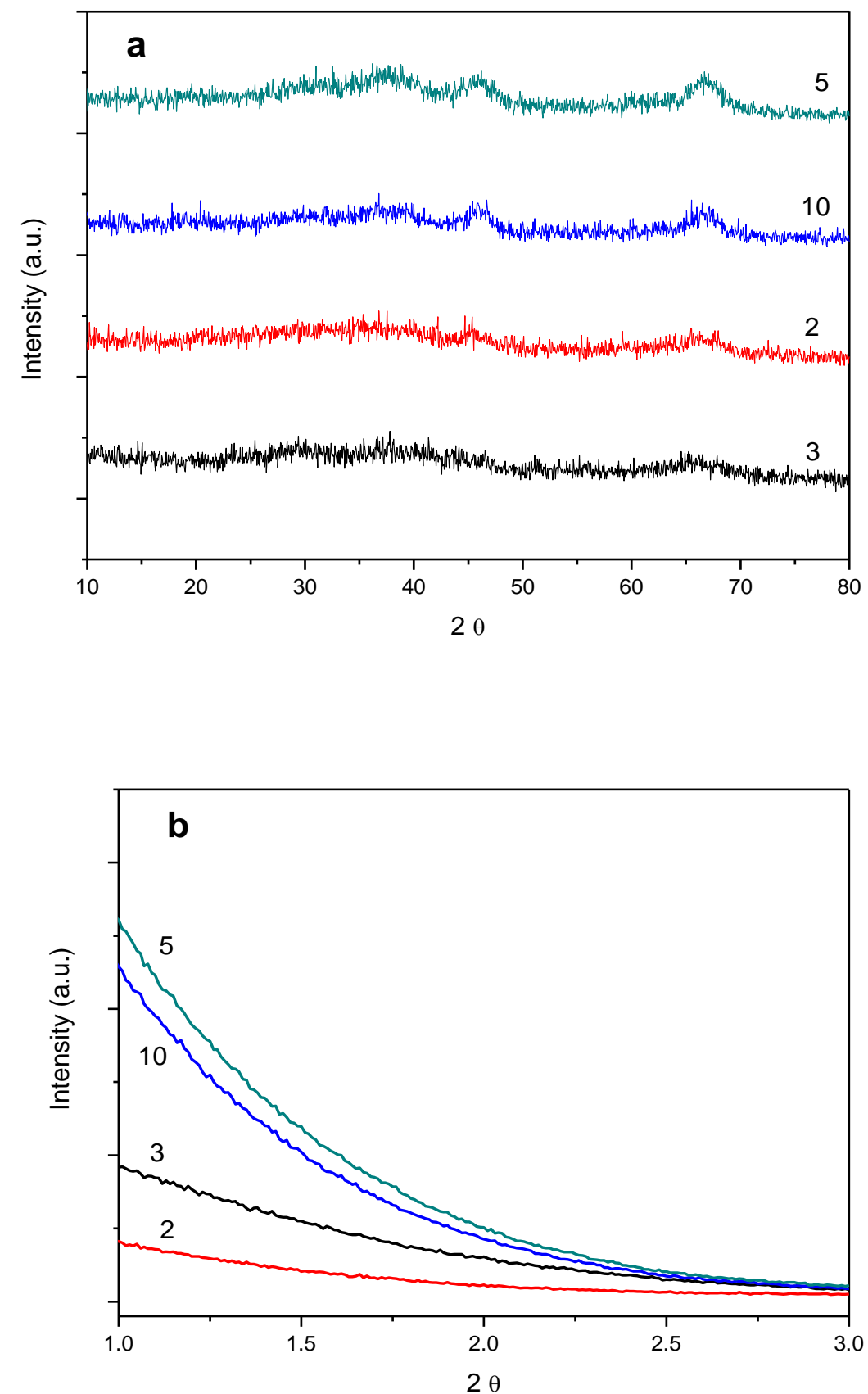